\title{
Hubungan Teknik Pernafasan dengan Kemajuan Persalinan
}

\section{The Correlations of Breathing Techniques With The Progress of Childbirth}

\author{
Ika Putri Damayanti
}

\section{Program Studi DIII Kebidanan STIKes Hang Tuah Pekanbaru}

\begin{abstract}
ABSTRAK
Teknik Pernafasan merupakan teknik yang dapat bermanfaat untuk mengatasi rasa nyeri persalinan sehingga ibu tidak kewalahan saat mengalami kontraksi, selain itu teknik pernafasan juga dapat membantu proses persalinan agar berjalan dengan normal. Berdasarkan studi pendahuluan di BPM Deliana S. dari 218 orang terdapat 16 orang (8\%) ibu bersalin mengalami kesulitan dalam mengatur teknik pernafasan dengan benar di saat mengedan sehingga menyebabkan kala II terhambat. Tujuan penelitian ini yaitu untuk diketahuinya hubungan antara teknik pernafasan dengan kemajuan persalinan. Jenis penelitian yang digunakan dalam penelitian ini adalah analitik kuantitatif dengan desain penelitian cross sectional. Populasi dalam penelitian ini yaitu seluruh ibu bersalin pada tahun 2015, dengan sampel ibu bersalin dari Januari - Maret tahun 2015 yang berjumlah 63 orang. Dan menggunakan analisa data bivariat dengan uji chi square test. Hasil penelitian dapat diketahui bahwa dari 39 responden yang menggunakan teknik pernafasan yang benar mayoritas mengalami kemajuan persalinan sebesar 32 responden $(82,1 \%)$, dengan nilai $p$-value $0,004(p<0,05)$, berarti ada hubungan antara teknik pernafasan dengan kemajuan persalinan. Kesimpulan penelitian ini ada hubungan teknik pernafasan dengan kemajuan persalinan, sehingga teknik pernafasan penting diterapkan dalam proses persalinan untuk dapat membantu memperlancar proses persalinan.
\end{abstract}

Kata kunci : Teknik Pernafasan, Kemajuan Persalinan.

\section{ABSTRACT}

Breathing techniques is a technique that can be useful to overcome the pain of childbirth. So that, mother was not overwhelmed when having contractions, besides that technical breathing also help the process of childbirth to run normally. Based on preliminary studies on BPM Deliana S. of 218 peoples be found 16 peoples (18\%) maternal have difficulty in breathing techniques set properly when straining causing the second time is obstructed. The purpose of this research is to know the corelations between breathing technique with the progress of childbirth. The kind of research is all of maternal in 2015, with a maternal sampling from January to March 2015 that amount 63 peoples. And using bivariate analysis by using chi square test. Results of this research is that of the 39 respondents who uses correct breathing techniques majority of the progress of labor by 32 respondents $(82.1 \%)$, with a p-value of $0.004(p<0.05)$, means that there is a relationship between breathing techniques with progress childbirth. The conclusion is any correlation between breathing techniques with the progress of childbirth, so that the breathing techniques was important to applied in the childbirth process to be able to help the process of childirth.

Keywords : Breathing Techniques, Progress of Childbirth

\section{PENDAHULUAN}

Teknik Pernafasan adalah salah satu keterampilan yang paling bermanfaat untuk mengatasi rasa nyeri persalinan. Keterampilan relaksasi pernafasan untuk mengatasi rasa nyeri ini dapat digunakan selama persalinan agar dapat mengatasi persalinan dengan baik berarti tidak kewalahan atau panik saat menghadapi rangkaian kontraksi (Maryunani, 2010).

Relaksasi pernafasan selama proses persalinan dapat mempertahankan komponen sistem saraf simpatis dalam keadaan homeostatis sehingga tidak terjadi peningkatan suplai darah, mengurangi kecemasan dan ketakutan agar ibu dapat beradaptasi dengan nyeri selama proses persalinan (Maryunani, 2010).

Setiap pasien yang bersalin selalu menginginkan terbebas dari rasa nyeri akibat his.Hal yang perlu ditekankan pada pasien adalah bahwa tanpa ada rasa nyeri maka persalinan tidak akan mengalami kemajuan, karena salah satu tanda persalinan adalah

\footnotetext{
${ }^{1}$ Alamat Korespodensi: Ika Putri Damayanti, Email: ikaputridamayanti@gmail.com
} 
adanya his yang akan menimbulkan rasa sakit. Beberapa upaya yang dapat ditempuh seperti mandi dengan air hangat, berjalan-jalan di dalam kamar, duduk di kursi sambil membaca buku atau novel kesukaan, posisi lutut-dada di atas tempat tidur, dan sebagainya (Sulistyawati, 2010).

Kemajuan persalinan adalah keadaan dimana terjadinya dilatasi serviks yang biasanya dapat diukur dengan jari (1 jari sama dengan $1 \mathrm{~cm})$. Dilatasi diukur dari 1-10 cm, dan dilatasi dikatakan sudah lengkap apabila sudah mencapai $10 \mathrm{~cm} \quad$ (Stoppard, 2008 ). Ada beberapa faktor yang dapat mempengaruhi kemajuan proses persalinan seperti pengaturan posisi pasien, kehadiran pendamping, latihan bernafas, usapan pada punggung, serta usapan pada abdomen (Sulistyawati, 2010).

Dari hasil studi pendahuluan di dapatkan data bahwa jumlah pasien yang sudah bersalin di BPM Deliana S. selama tahun 2014 sebanyak 218 orang. $100 \%$ dari jumlah tersebut diajarkan teknik relaksasi pernafasan sejak kala I sampai kala II. Dari 218 orang, terdapat $202(92 \%)$ orang yang berhasil melakukan teknik pernafasan dengan baik sesuai tahapannya dan didapatkan kemajuan persalinan yang tidak melewati garis waspada pada partograf. Dan 16 orang (8\%) lainnya mengalami kesulitan dalam mengatur teknik pernafasan di saat mengedan sehingga menyebabkan kala II sedikit terhambat.

Berdasarkan studi pendahuluan yang dilakukan peneliti di beberapa tempat praktek bidan, peneliti melihat bidan yang mengajarkan teknik pernafasan kepada pasien pada kala 1 untuk membuat pasien rileks dan dapat mengontrol rasa nyerinya. Selain itu, di kala 2 juga bidan selalu memimpin pasien agar dapat bernafas dengan cara yang benar, yang mana ketika pasien sulit mengontrol pernafasan saat mengedan maka hasilnya kepala janin akan sulit dilahirkan, sedangkan ketika pasien sudah dapat mengontrol nafasnya dengan benar, maka pasien akan dengan mudah melahirkan kepala janin.

Dari latar belakang di atas, peneliti tertarik untuk meneliti tentang Hubungan tekhnik pernafasan pada ibu bersalin dengan kemajuan persalinan. Tujuan penelitian ini adalah untuk diketahuinya hubungan antara tehnik pernafasan dengan kemajuan persalinan di BPM Deliana S.Pekanbaru tahun 2015.

\section{METODOLOGI}

Jenis penelitian yang digunakan dalam penelitian ini adalah analitik kuantitatif yang bertujuan untuk mengetahui hubungan antara teknik pernafasan pada ibu bersalin dengan kemajuan persalinan di BPM Deliana S.Pekanbaru Tahun 2015.

Desain penelitian ini adalah cross sectinal yaitu mengidentifikasi hubungan teknik pernafasan pada ibu bersalin dengan kemajuan persalinan dengan pengumpulan data dari kasus persalinan yang sudah terjadi sebelumnya. Penelitian ini dilaksanakan di BPM Deliana S Pekanbaru. Populasi dalam penelitian ini yaitu seluruh ibu bersalin di BPM Deliana S pada tahun 2015. Sampel dalam penelitian ini adalah ibu bersalin di BPM Deliana S pada bulan Februari Maret 2015 yang berjumlah 63 orang.

Sumber data dalam penelitian ini adalah data primer yang didapatkan melalui observasi pada ibu bersalin. Analisis data digunakan analisa Univariat dan analisa Bivariat. Analisa Univariat bertujuan untuk menjelaskan atau mendeskripsikan karakteristik setiap variabel penelitian meliputi variabel independen ( kemajuan persalinan ), variabel dependen (teknik pernapasan). Sedangkan analisa Bivariat yang dilakukan terhadap dua variabel yang diduga berhubungan atau berkorelasi, dalam penelitian ini adalah variabel independen (kemajuan persalinan) dengan variabel dependen (teknik pernafasan). Dalam analisa ini dapat dilakukan pengujian statistik chi square test, karena dalam penelitian ini variabel yang dihubungkan dalam bentuk kategorik. Dengan tingkat kepercayaan $95 \%(\alpha=0,05)$.

\section{HASIL}

\section{Analisa Univariat}

Dari 63 responden yang mengalami kemajuan persalinan sebanyak 45 orang $(71,4 \%)$. Dan dari 63 responden yang melakukan teknik pernafasan dengan benar sebanyak 39 orang $(61,9 \%)$, yang dapat dilihatpada tabel di bawah ini.

Tabel 1

Hasil Analisis Univariat

\begin{tabular}{ccc}
\hline Variabel & F & \% \\
\hline Kemajuan Persalinan & & \\
Ya & 45 & 71,4 \\
Tidak & 18 & 28,6 \\
Total & 63 & 100 \\
Teknik Pernafasan & & \\
Benar & 39 & 61,9 \\
Tidak Benar & 24 & 38,1 \\
Total & 63 & 100 \\
\hline
\end{tabular}

\section{Analisa Bivariat}

Dari hasil penelitian diketahui bahwa dari 39 responden yang menggunakan teknik pernafasan yang benar mayoritas mengalami kemajuan persalinan sebesar 32 responden $(82,1 \%)$, dan dari 24 responden yang tidak menggunakan teknik pernafasan dengan benar tidak mengalami kemajuan persalinan sebesar 11 responden $(45,8 \%)$.

Setelah dilakukan uji statistik dengan chi square test, maka diperoleh nilai p-value adalah 0,004 $(\mathrm{p}<0,05)$, yang berarti bahwa ada hubungan antara teknik pernafasan dengan kemajuan persalinan, yang dapat dilihat dari tabel 2 . 
Tabel 2

Hubungan Teknik Pernafasan dengan Kemajuan Persalinan di BPM Deliana S. Pekanbaru Tahun 2015

\begin{tabular}{cccccccc}
\hline \multirow{2}{*}{ Teknik Pernafasan } & \multicolumn{6}{c}{ Kemajuan Persalinan } & \multirow{2}{*}{ Uji Statistik } \\
\cline { 2 - 7 } & \multicolumn{3}{c}{ Ya } & \multicolumn{3}{c}{ Tidak } & \multicolumn{2}{c}{ Total } & \\
\cline { 2 - 7 } & $\mathrm{F}$ & $\%$ & $\mathrm{~F}$ & $\%$ & $\mathrm{~F}$ & $\%$ & P value \\
\hline Benar & 32 & 82,1 & 7 & 17,9 & 39 & 100 & \\
Tidak Benar & 13 & 54,2 & 11 & 45,8 & 24 & 37 & 0,004 \\
Total & 45 & 71,4 & 18 & 28,6 & 63 & 100 & \\
\hline
\end{tabular}

\section{PEMBAHASAN}

\section{Hubungan Teknik Pernafasan dengan Kemajuan Persalinan}

Dari hasil penelitian diketahui bahwa dari 39 responden yang menggunakan teknik pernafasan yang benar mayoritas mengalami kemajuan persalinan sebesar 32 responden $(82,1 \%)$, dan dari 24 responden yang tidak menggunakan teknik pernafasan dengan benar tidak mengalami kemajuan persalinan sebesar 11 responden $(45,8 \%)$. Dan setelah dilakukan uji statistik dengan chi square test, maka diperoleh nilai $p$-value adalah $0,004(p<0,05)$, yang berarti bahwa ada hubungan antara teknik pernafasan dengan kemajuan persalinan.

Pada kelas-kelas kehamilan biasanya diajarkan bagaimana relaksasi dan menguasai berbagai teknik-teknik bernafas. Ibu berslin dapat menggunakan masing-masing teknik pada waktu yang berbeda selama persalinan untuk membantu anda rileks, menghemat energi, mengendalikan badan anda dan rasa sakit, menenangkan diri sehingga proses persalinanpun dapat berjalan dengan normal ( Stoppard, 2008 ).

Teknik adaptasi pola nafas dapat efektif jika pikiran dan tubuh tenang, sehingga oksigen bersama darah mengalir ke seluruh tubuh. Aliran oksigen yang lancar akan mempengaruhi kontraksi uterus lebih efektif dan teratur, sehingga persalinan menjadi lebih cepat. Ketersediaan oksigen mempengaruhi aktifitas kontraksi uterus, semakin banyak oksigen yang ditransfer ke otot rahim maka kontraksi uterus semakin adekuat sehingga persalinan menjadi lebih singkat (Maryunani, 2010).

Penelitian ini sesuai dengan hasil penelitian Suryanti, dkk (2013) tentang "Teknik Adaptasi Pola Nafas Terhadap Penurunan Intensitas Nyeri dan Memperlancar Proses Persalinan di RSUD Cilacap Tahun 2013" didapatkan hasil terdapat perbedaan yang signifikan waktu persalinan antara kelompok ibu bersalin yang diberikan tehnik adaptasi pola nafas dengan ibu bersalin yang tidak diberikan tehnik adaptasi pola nafas pada ibu bersalin di RSUD Cilacap $(\mathrm{p}=0,019<0,05)$.
Penelitian ini juga sejalan dengan hasil penelitian Susiloningtyas (2011) yang berjudul "Pengaruh Teknik Relaksasi Terhadap Lamanya Proses Persalinan di BPS Endang S. Priyono Desa Duwet Kecamatan Wates Kabupaten Kediri Tahun 2011 yang menyatakan bahwa ada hubungan yang kuat yang didapat melalui rumus korelasi Spearman diperoleh 0,658 dengan uji signifikasi (p) 0,008 dengan taraf signifikan $95 \%$.

Peneliti berasumsi bahwa ibu yang menggunakan teknik pernafasan selama proses bersalin maka akan membantu proses persalinannya berjalan dengan lancar. Pada saat melakukan penelitian dengan cara observasi langsung, peneliti melihat bahwa ibu yang menjalankan persalinannya dengan tenang dapat menahan rasa nyerinya dengan baik sehingga kemajuan persalinannya pun bisa berjalan lancar, sedangkan ibu yang mengutamakan rasa cemas, takut, dan gugup merasakan nyeri yang berlebihan sehingga kemajuan persalinannya sedikit terhambat karena ibu yang tidak dapat mengontrol emosi dan berteriak setiap ada kontraksi.

Selain itu terlihat bahwa teknik pernafasan saat mengedan juga mempunyai hubungan dengan maju atau tidaknya persalinan tersebut karena kebanyakan ibu yang salah atau tidak tepat saat melakukan teknik pernafasan saat mengedan dapat menyebabkan waktu kala II persalinan yang lebih lama dibandingkan ibu yang menggunakan teknik pernafasan dengan benar.

\section{KESIMPULAN}

Berdasarkan hasil uji statistik dengan chi square test, maka diperoleh nilai $\mathrm{p}$-value adalah 0,004 $(p<0,05)$, yang berarti bahwa ada hubungan antara teknik pernafasan dengan kemajuan persalinan.

\section{SARAN}

Bagi BPM diharapkan hasil penelitian ini dapat menjadi tolak ukur bagi pelayanan kebidanan khususnya di BPM Deliana S. agar mampu meyakinkan pasien yang bersalin untuk dapat mengikuti teknik pernafasan dengan benar sesuai 
dengan yang diajarkan oleh bidan, serta menjelaskan manfaat dari teknik pernafasan tersebut yang dapat membantu untuk kemajuan persalinan dan memperlancar proses persalinan. Bagi Pendidikan Kebidanan, diharapkan agar karya hasil penelitian ini menjadi informasi tambahan bagi mahasiswa kebidanan sehingga mahasiswa dapat mengaplikasikannya teori yang telah didapatkan saat berada di lahan praktek. Bagi Peneliti Selanjutnya, diharapkan peneliti dapat menambah sumber atau referensi yang mendukung tentang adanya hubungan teknik pernafasan dengan kemajuan persalinan. Serta lebih menggali lagi permasalahan tentang teknik pernafasan pada saat persalinan, dapat juga menambah variabel penelitiannya.

\section{UCAPAN TERIMAKASIH}

Penulis mengucapkan terimakasih pada pembimbing, penguji 1 dan penguji 2 yang telah memberikan bimbingan dan masukan dalam menyelesaikan penelitian ini. Kepada pihan BPM Deliana S. Pekanbaru yang telah memberikan izin terkait hubungan teknik pernafasan dengan kemajuan persalinan di BPM Deliana S. Pekanbaru.

\section{DAFTAR PUSTAKA}

Maryunani Anik (2010). Nyeri Dalam Persalinan, Teknik, Dan Cara Mengatasinya. Jakarta: Trans Info Media.

Notoatmodjo Prof. Dr. Soekidjo (2010). Metodologi Penelitian Kesehatan. Jakarta: Rineka Cipta.

Stoppard Dr. Miriam (2008). Buku Pintar Kehamilan \& Persalinan Modern. Yogyakarta: Quills Book Publishers.

Sugiono (2007). Statistika Untuk Penelitian Cetakan Kedua Belas Revisi Terbaru. Bandung: Alfabeta.

Suryanti, dkk (2013). Teknik Adaptasi Pola Nafas Terhadap Penurunan Intensitas Nyeri Dan Memperlancar Proses Persalinan, (Online), (http://www.akbidylpp.ac.id/index.php/Prada/art icle/view/83, diakses Desember 2013).

Susiloningtyas, (2011). Pengaruh Teknik Relaksasi Terhadap Lamanya Proses Persalinan, (Online), (https://www.scribd.com $>$ mobile $>$ doc, diakses November 2013 ). 